\title{
Impact Of The Placement And Quality Of Face-To-Face Meetings In A Hybrid Distance Learning Course
}

William Colucci, Ph.D., Montclair State University, USA Nicole Koppel, Ph.D., Montclair State University, USA

\begin{abstract}
As online and hybrid courses are becoming a wide-spread option for higher education, researchers are exploring various delivery methods. Hybrid courses involve blending two modes of interaction -both face-to-face as well as online. The exact distribution and timing of face-toface meetings verse online delivery is a question that instructors have been struggling with since the inception of hybrid courses. This paper reports findings from a study evaluating course outcomes in an undergraduate business computer applications course based on the quality and quantity of face to face meetings at the beginning of the course.
\end{abstract}

Keywords: hybrid course; distance learning; computer training; application training; blended learning; instructional design

\section{INTRODUCTION}

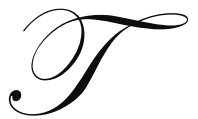

his study examines whether changes to a hybrid course structure providing greater quality and quantity of face to face interaction at the begging of the course has direct or indirect impacts on outcomes. Advocates of hybrid courses argue that they combine the best features of face-to-face as well as online courses (Menchaca \& Bekele, 2008; Graham and Dziuban, 2008). One advantage of face-to-face meetings, it is argued, is the opportunity to increase student motivation through social identification with the course, peers and the instructor. Establishing social identification, roles and relationships is easier through face to face meetings than through computer mediated communication (Garrison \& Vaughn, 2008). Face to face meetings might be a way not only to make students feel greater identification with the course, but also to provide greater comfort or more effective information about the online components of hybrid courses for those students without any experience in distance learning. Therefore, it may be that the scheduling of face to face meetings in a hybrid course is important. Face to face meetings in the beginning of a course in particular can serve to establish social identification for motivation and increase comfort and information about the format of the course to students. These factors should lead to better outcomes, typically assessed in terms of grades, satisfaction with the course and satisfaction with the hybrid format itself.

This study looks at the impact of increasing face to face meetings in a hybrid course teaching Microsoft Office 2007 to undergraduates at a major Eastern public university. Some sections of this course were carried out with two additional mandatory face to face meetings at the beginning of the course. In addition, these meetings were of greater quality than those contained in the control sections. The control sections met only for exams which were proctored events, not allowing for free peer or student to instructor interaction. Students had the freedom to interact with other students and the instructors at will while doing a class exercise assignment. Differences in mean grade scores and end of class satisfaction survey items were analyzed. No positive difference in mean grade or satisfaction scores were found. Possible reasons for this are discussed, along with post hoc analyses. Results suggest caution regarding assumptions about the role and utility of face to face meetings in a hybrid course. 


\section{LITERATURE REVIEW}

Courses taught entirely or partially via computer mediated interaction (synchronous and asynchronous) are increasingly being used by Universities to provide access to education to a wider array of students, reduce costs and provided added-value ( Graham and Dziuban, 2008; Senn, 2008).

Hybrid courses involve blending two modes of interaction -both face-to-face as well as computer mediated interaction (both synchronous and asynchronous). Speculation and research have suggested or shown advantages and disadvantages for each mode. Combining both modes in a blended or hybrid course structure is seen as a potential opportunity (Dziuban, et al., 2006; Graham and Dziuban, 2008). Research on the relative effectiveness of hybrid vs. face to face vs. purely online courses reports that hybrid models are associated with comparable or superior outcomes (Graham and Dziuban, 2008). A hybrid course might be designed to realize the advantages and mitigate disadvantages of each mode in course design - "Research related to better understanding the nature of human interaction in blended learning environments is a promising direction of inquiry" (pg. 274).

In a review of research on face to face compared to asynchronous computer mediated interaction, Garrison $\&$ Vaughn (2008) suggest that each mode of interaction has advantages and disadvantages. Face to face modes are superior for establishing 'social presence' involved in motivation and commitment, in establishing roles, and in brainstorming - generating ideas and sharing information. Asynchronous computer mediated discussions allow greater time and effort to be put into assessing communicative interactions and provide for more deliberative and complex contributions and interactions. The implications from these studies suggests that face to face modes of interaction be used to help create motivation and share information efficiently. That implies that scheduling face to face sessions in the beginning of a hybrid class might give hybrid classes an advantage over fully computer mediated modes in terms of student commitment to the course and understanding of the course structure and process.

Menchaca \& Bekele (2008) recommend a particular structure or use of each mode in a hybrid course. In a report on research into the factors identified by students as well as instructors in the online learning environment outcomes, they suggest that face to face has the advantage of building motivation among students. Face to face modes of interaction (vs. computer mediated a/synchronous interaction) is seen as superior in building commitment to the course and course structure. This occurs through superior ability to develop a sense of 'community' emotional relational support, ties or identification. In addition, greater sense of comfort and willingness to use technology might be an outcome.

Menchaca \& Bekele (2008) find students and teachers reporting that face-to-face meetings at the beginning and end of hybrid courses were most important (pg. 248). Their summary of findings includes a critical role for face-to-face modes in courses: “...successful OLEs should:

- Integrate multiple tools for different contexts;

- $\quad$ Promote a positive attitude toward technology and OLE;

- Incorporate a social and situated learning environment;

- $\quad$ Include some level of f2f interaction;

- $\quad$ involve and rely on faculty at many levels;

- $\quad$ Help participants develop appropriate skills, experience, and training; and

- $\quad$ Provide sustained administrative support;" (pg. 249)

Given these criterion, face to face modes of hybrid course interaction might not only have a role in enhancing many of these elements of good course design, but indeed is listed as a discreet element itself.

Krumrow (2007) uses data source similar to Menchaca \& Bekele (2008) - graduate nursing courses to look at whether differences in face-to-face vs. hybrid modes had an impact on outcomes. He found that the hybrid course format had better outcomes - satisfaction with the course and grades. He analyzed the ability for students to regulate their own learning given the increased isolation (at least in contrast to face to face modes of interaction) that hybrid courses represent. In particular, he looked at student management of resources to test whether the decreased 
face to face contact of the hybrid course format affected students less capable or willing to manage their own study strategies. He found that only students 'help seeking' strategies were positively associated with final grades and had a significant higher mean at the end of the course compared to the beginning. He argues that this suggests that students did not have to adjust their strategies for managing their learning with the exception of 'help seeking', speculating that they might have felt that the hybrid format increased a sense of isolation and students felt a need to increase efforts to get help. Huang (200?) found that perceptions self directed learning ("learner autonomy") was associated with measures of satisfaction with on-line courses. "Learner autonomy" was in turn related to positive perceptions regarding relationships with others (interdependence), i.e., instructors, groups, peers.

One limitation of these studies is that they all involve graduate students and do not directly involve the course content addressed in this paper. Menchaca \& Bekele (2008) developed their assessment from interviews with teachers and students in graduate management and information systems courses. Krumrow (2007) looked at graduate nursing courses. Huang (2002) looks at business and education graduate courses. Krumrow (2007) and Huang (2002), as well as general reviews of studies of hybrid courses (D..., 2008) suggest that in an online or hybrid course, outcomes are determined in part by student confidence and/or ability to meet an increased need work autonomously, or in a self-regulated manner. Menchaca \& Bekele's (2008) work suggests that face to face modes of interaction in particular might be optimal for helping students bridge motivational, study strategy and technical proficiency gaps. In particular, it is suggested that building a sense of community, identification with the course, and resolving technical issues early in a course via face to face meetings would be helpful.

\section{OVERVIEW OF COURSE}

This study analyzes undergraduates, indeed largely freshman and sophomores, in an introductory course in the Management and Information Systems department. The course is an introduction to Microsoft Office 2007 Word, Powerpoint, Excel and Access - basic business applications (Microsoft Office 2007). The course is taught in an AACSB-accredited business school at a large state university on the East Coast located in a suburban environment.

The Introduction to Computers in Business Course is a required general education course for all students with a business administration major. Each semester, over 300 students enroll in this hybrid course. There are three large sections in this course -- two day sections, one on Tuesday and one on Thursday, and one evening section. Each large section has between 90 and 120 students. All of the students in a large section have a common meeting time scheduled in a large lecture hall. In addition, each section is subdivided into four subsections, each with a unique meeting time in a 30-person computer lab. The course content consists of three modules including Word/PowerPoint, Excel, and Access. The majority of learning is done via online tutorials. However, four face-toface lectures are required in the large lecture hall. These include an initial class meeting introducing the course format and three content lectures, one in Excel and two in Access. In addition, students are required to attend their assigned computer lab subsection on three or four specified dates. The typical format is that the students would be required to attend the computer lab on their three exam dates. Besides these seven or eight required meetings, the computer lab is open two days and one evening each week for all students enrolled in this course to complete online tutorials or other required assignments. During these times, the course instructor plus two graduate assistants are available to answer questions and provide assistance to students.

Course requirements include completion of online tutorials, three online exams corresponding to the three course modules, three case studies corresponding to the three course modules requiring students to apply the software skills to "real" business situations, and seven homework or practice assignments. Blackboard is used as the course management system. At the end of the semester, students in each section completed an anonymous online course evaluation survey.

\section{MODEL}

Students with low levels of motivation, experience and study skills should respond greater to the strategic use of face to face meetings in hybrid courses (Menchaca \& Bekele's, 2008). In particular, structuring a hybrid course so that face to face meetings might provide a better forum for the following. In terms of motivation - or 
"buy-in" - willingness to complete assignments and invest time and effort into addressing assignments - might be enhanced by building identification with the course, instructor and peers at the beginning of the class through face to face meetings. Students may spend more time studying, be encouraged to visit with instructors or peers during lab hours, or spend more time using online tutorials. Face to face meetings might also be the best way to address any gaps in proficiency in using the courseware interface (in this case Blackboard), web based resources (tutorials and tests in this case), and utilizing personal computer hardware/software. These meetings might be more effective in addressing and resolving technical problems or questions.

Thus, increased quality and quantity of face to face meetings at the beginning of the course should be related to course outcomes. These include grades, "buy-in" (reduced missed assignments), increased satisfaction with the hybrid format of the course and increased satisfaction with resources provided by the course. The lower the resources students bring to a hybrid course, the stronger this relationship should be. Factors likely to be related to lower student resources include family background (Perna \& Thomas, 2008). This might be a factor in this case given that the students addressed in this research are from an suburban state university system, students tend to come from lower socio-economic strata with generally less family experience or support for higher education. Other factors include (Huang, 2002) age, credits completed, number of previous courses in an area, experience with computers in general, experience with the particular type of computer programs addressed by the course, general academic capability marked by grade point average. This study indeed analyzes data drawn from a sophomore (200 level) course - i.e., of students least experienced - largely freshman and sophomores. Those students are less likely to have general computer experience, experience with hybrid/online courses, and experience/skill as students probability of lower levels of skills as autonomous and self-motivated learners. These students might rely more than others on external prompts found in typical face to face courses for discipline, prioritizing, and scheduling.

Thus, the general goal of this paper is to test whether changes to a hybrid course structure providing greater quality and quantity of face to face interaction at the begging of the course has direct or indirect impacts on outcomes. This might be so given speculation on the relatively superior ability of that mode of interaction to foster "buy-in" (motivation, identification with the course), increased proficiency with computer technology and courseware/interface, and taking greater advantage of course resources (e.g., visiting during lab hours), more investment of time in the course (studying more, putting more time into tutorials).

Hypothesis 1. Students in the treatment group will have more positive mean outcomes than the control group after the treatment period (first module - Word/Powerpoint).

a. $\quad$ Case study grades will be higher: Each case study, average of case study grades.

b. Homework grades will be higher.

c. Less overall assignments will be missed (required lecture attendance, homework assignments, exams, case studies, required tutorials): Each category, sum of categories.

Hypothesis 2. Students will have a more positive view of course resources (Instructor/graduate assistant accessibility/knowledge; Textbook useful; Online tutorials useful).

Hypothesis 3. Students will be more motivated to invest time and effort into course work (greater "buy-in").

a. $\quad$ Higher mean level of hours study reported by students.

b. $\quad$ Higher mean number of visits to the lab reported by students.

c. Greater time spent with tutorials.

\section{DESIGN}

This study will look at the structure of hybrid courses in terms of the quality and structural location of face to face meetings in a course. In particular, we look at whether additional meetings at the beginning of the course, and of greater quality of interaction, has an effect on outcomes. Outcomes measured include grades on major projects assigned heaviest weight in this class (case studies), overall course grade, commitment to the course (whether students completed assignments), as well as satisfaction with the hybrid course format (whether they 
thought the hybrid format was appropriate for learning in this course and whether they would likely take another hybrid course).

This study only examines the two day course sections - the Tuesday section and the Thursday section. A previous study found no statistically significant mean difference between Tuesday and Thursday sections of this class in terms of GPA, grades, credits taken, or transfer status (Hollister and Berenson, 2009). In order to examine the affects of providing greater quality and quantity of face to face interaction at the begging of the course, the format of the Tuesday section was changed from the typical format as described above.

All Tuesday sections were treated separately from Thursday sections- separate syllabus, separate communication (email, and web based support (i.e., Blackboard course)). Tuesday (treatment) sections were given a syllabus that required students to come to lab hours at specified times to carry out homework assignments in class. These students took tests remotely (via a web based service), rather than meeting in a proctored - face to face - test in the lab, as the control group (Thursday section) was asked to do. In addition, students in the Tuesday section were required to come to face to face meetings in class one time more often than Thursday students, and more often in the beginning of the course.

The quality of the face to face meetings was altered by changing the type of task and the forum for the task that the face to face meeting was associated. The course had been designed originally to include face to face meetings only during lectures in large lecture halls (over 100 students per lecture), and during proctored tests. These face to face meetings provided little ability for students to interact with instructors or peers. The treatment section was modified as follows. Three low interaction face-to-face meetings (exams) were moved to online exams students did individually over the internet. Four of 7 homework assignments - previously done individually and submitted over the internet - were assigned as required in-class sessions. Homework assignments were given additional weight in terms of grading (from $1 \%$ to $2 \%$ each). Students were given access to assignments before class to practice if they wished, but had to do the assignments in class from scratch.

Table 1

Schedule of treatment and control groups*

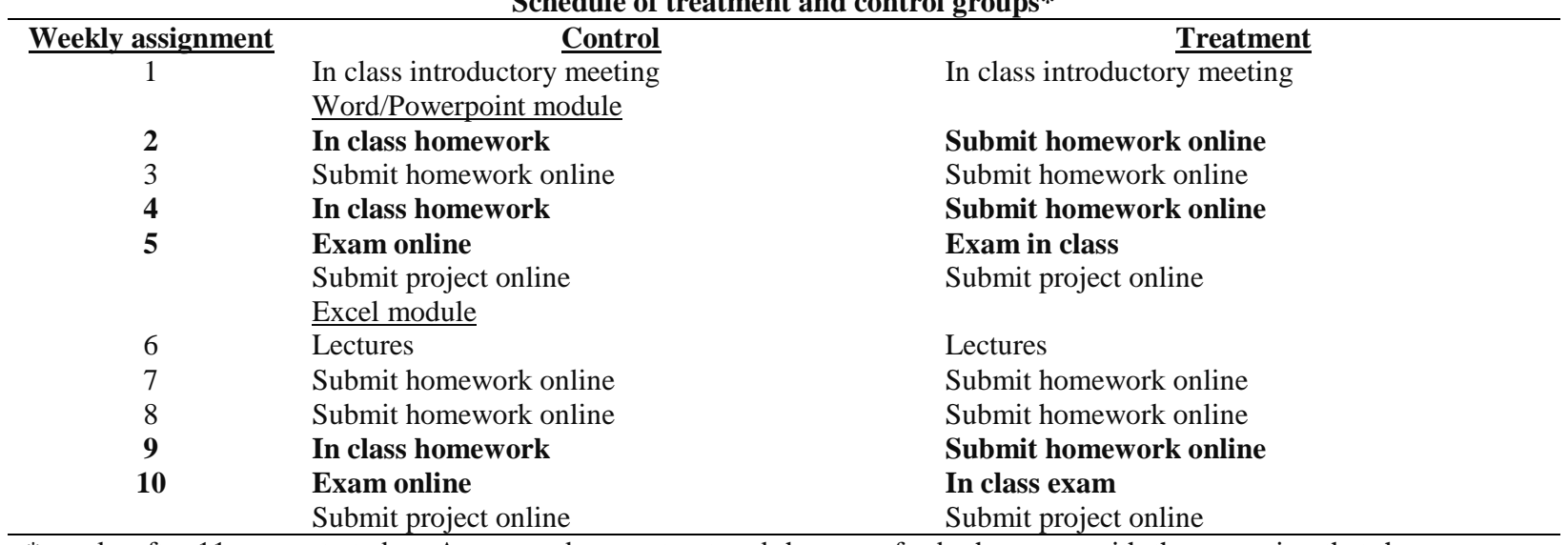

* weeks after 11 concentrated on Access and were structured the same for both groups with the exception that the exam was done in class for control group and online for treatment group.

The treatment section was required to come into the lab (a class limited to 30 students with computers). These meetings were not proctored in any sense except in ensuring that students came to class and carried out the assignment in the one hour and fifteen minute time period for their section in the lab. Students were encouraged to freely interact with and get help from with the instructors - a professor and two graduate assistants - as well as each other, and to use any computer or written material they might want. The structure of the treatment group course was altered to provide more face-to-face meetings with greater interaction (required in class homework assignments) encouraged at the beginning of the course. See Table 1 below for a comparison of the schedules of treatment and 
control groups. Both groups had a face-to-face, in class, introductory meeting the first week of class. Following that, the treatment group met in class to do the homework in week 2, 4 - two additional face to face meetings at the beginning of the course. This was followed up by a face to face meeting on week 10, just before a major test and project was due. The control group in contrast met face to face later, fewer times and with little or no interaction facilitated (proctored exams). Lectures were carried out in large lecture halls with over 100 students in attendance (lecture attendance was required).

\section{MEASURES}

\section{Outcome measures}

\section{Grades}

Case Study. Grades on the most heavily weighted and difficult assignments (called "Case Studies") were used. Case studies were made available at least two weeks before they were due, and were carried out by downloading instructions and files from/to the university online course management system (Blackboard, using the assignment feature) to manipulate, then uploading the products of that manipulation. No difference in mean grades for case studies overall or individually was found in previous semesters for this course for the same sections (day and time each section was supposed to meet).

Homework. Homework assignments were made up of step by step instructions and a document to work on. They are designed to give students hands-on experience with major concepts addressed in exam and project (case study) assessments. While some homework assignments were part of the treatment, others were not. Those that were not were used as outcome variables.

Course "buy-in" - Completing assignments. The number of assignments (homework, case studies, tests, lectures) missed was counted. Assignments missed after the treatment period (during the first module or the first few weeks of the course) should be lower for the treatment group. Overall assignments missed and assignments by categories were examined.

Course "buy-in" - Effort. Study hours reported in course evaluation survey at the end of the semester (which were not anonymous), visits to lab (course evaluation survey), completing training videos (online service provided data about whether videos were 'completed', meaning whether the student clicked through all sections of the video), time with training videos (online service data).

Satisfaction with the hybrid course format. Two questions given in the course evaluation survey address satisfaction with the hybrid class format, using a likert scale from Strongly Agree to Strongly Disagree:

- $\quad$ Regarding the Hybrid format of the course - the self-paced format of the course was appropriate for this course;

- I would consider another course that is offered in a hybrid course format.

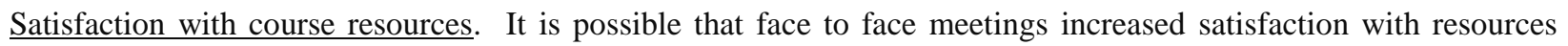
provided students, both computer mediated and otherwise. This includes the web based tutorials used by students, knowledge and accessibility of instructors, quality of texts. Analysis of the set of questions about course resources via factor analysis discerned a of resources that were found to consistently load together in data across semesters for this course: Professor accessible, GA accessible, Professor knowledgeable, Homework useful for reinforcing learning, and Tutorials useful (Cronbach's Alpha .69 in a previous semester, .66 in the semester studied). This outcome variable was therefore measured with a mean of these items. 
Table 2

Descriptive Statistics

\begin{tabular}{|c|c|c|c|c|c|}
\hline Outcome category/variable & $\underline{N}$ & $\underline{\text { Min. }}$. & $\underline{\text { Max. }}$. & $\underline{\text { Mean }}$ & $\underline{\text { Std. Deviation }}$ \\
\hline \multicolumn{6}{|l|}{ Grades } \\
\hline Homework 4 - Excel & 101 & 44 & 100 & 89.34 & 10.446 \\
\hline Homework 5 - Excel & 96 & 50 & 100 & 91.78 & 8.705 \\
\hline Excel case study & 101 & 3 & 108 & 78.34 & 23.786 \\
\hline Homework - Access & 104 & 19 & 100 & 86.91 & 16.652 \\
\hline Access case study & 102 & 2 & 100 & 86.05 & 17.473 \\
\hline \multicolumn{6}{|l|}{ Assessment of resources } \\
\hline $\begin{array}{l}\text { Mean of Professor knowledge, tutorials } \\
\text { useful, homework helpful, Professor } \\
\text { accessible, GA's accessible. }\end{array}$ & 107 & 2.80 & 5.00 & 4.2131 & .56118 \\
\hline \multicolumn{6}{|l|}{ Assessment of hybrid format } \\
\hline Hybrid Self Based Format appropriate & 108 & 0 & 5 & 4.07 & 1.117 \\
\hline Would consider a hybrid course again & 108 & 1 & 5 & 4.14 & 1.080 \\
\hline \multicolumn{6}{|l|}{ Buy-In } \\
\hline \multicolumn{6}{|l|}{ Study Effort } \\
\hline Overall Training Video Time & 108 & 0 & 1437 & 342 & 303 \\
\hline Number Of Lab Visits & 78 & 1 & 10 & 4.24 & 2.750 \\
\hline Hours Per Week Study & 108 & 0 & 10 & 2.69 & 1.655 \\
\hline \multicolumn{6}{|l|}{$\underline{\text { Sum of required assignments missed }}$} \\
\hline $\begin{array}{l}\text { Missed after two face to face meetings doing } \\
\text { homework (after homework } 3 \text { ) (sum) }\end{array}$ & 87 & 0 & 9 & 1.25 & 1.838 \\
\hline Missed overall (sum) & 108 & 0 & 10 & 1.74 & 2.277 \\
\hline Missed any exams (sum) & 108 & 0 & 1 & .02 & .135 \\
\hline Missed any case study (sum) & 108 & 0 & 3 & .31 & .662 \\
\hline Missed any homework (sum) & 108 & 0 & 4 & .41 & .762 \\
\hline Missed any tutorial (sum) & 108 & 0 & 5 & .78 & 1.233 \\
\hline Missed any Lecture (sum) & 108 & 0 & 3 & .23 & .540 \\
\hline
\end{tabular}

\section{CONTROLS}

Data relating to potential alternative explanations to hypotheses was addressed by analyzing whether statistically significant differences in means for the treatment and control groups was found for a range of variables. Treatment and control groups were assessed for differences in the following factors (see Table 3 for Descriptive Statistics):

Gender, number of courses in the area, previous experience with similar programs, number of credits taken in that semester, number of hours worked for pay, and a measure combining the latter two - number of credit hours $\mathrm{x}$ hours worked for pay - to get an overall idea of external commitments. None of these items were found to have statistically significant different means between the groups. GPA data was not available, but a study of the same course reported no difference in mean GPA scores between the same sections and days in a previous semester (Hollister and Berenson, 2009). 
Table 3

Descriptive Statistics

\begin{tabular}{|c|c|c|c|c|c|c|}
\hline & $\underline{\text { Treatment }}$ & $\underline{\mathbf{N}}$ & $\underline{\text { Minimum }}$ & $\underline{\text { Maximum }}$ & $\underline{\text { Mean }}$ & $\underline{\text { Std. Deviation }}$ \\
\hline & Gender $(1=\mathrm{F}, 2=\mathrm{M})$ & 36 & 1 & 2 & 1.42 & .500 \\
\hline & $\begin{array}{l}\text { Class Level } \\
(1=\text { Fresh... } 4=\text { senior })\end{array}$ & 24 & 1 & 4 & 2.37 & 1.245 \\
\hline & Hours Work For Pay Week & 35 & 0 & 35 & 12.60 & 10.126 \\
\hline & $\begin{array}{l}\text { Number Of Other College Courses } \\
\text { In the same Subject Area taken }\end{array}$ & 35 & 0 & 4 & .66 & .838 \\
\hline & Overall Credits This Semester & 61 & 3 & 19 & 13.33 & 4.625 \\
\hline & $\begin{array}{l}\text { Number Of Classes Taken This } \\
\text { Term }\end{array}$ & 36 & 3 & 7 & 4.92 & .874 \\
\hline & Hours Study Per Week & 31 & 0 & 32 & 3.77 & 5.560 \\
\hline & Hours Working For Pay Week & 62 & 0 & 75 & 16.69 & 14.659 \\
\hline & $\begin{array}{l}\text { Hours Working per week X } \\
\text { Credits taken this semester }\end{array}$ & 62 & 0 & 900 & 220.13 & 209.558 \\
\hline Control & & $\underline{N}$ & $\underline{\text { Minimum }}$ & Maximum & Mean & $\underline{\text { Std. Deviation }}$ \\
\hline & Gender $(1=\mathrm{F}, 2=\mathrm{M})$ & 39 & 1 & 2 & 1.44 & .502 \\
\hline & $\begin{array}{l}\text { Class Level } \\
(1=\text { Fresh... 4=senior })\end{array}$ & 22 & 1 & 4 & 2.27 & 1.120 \\
\hline & Hours Work For Pay Week & 39 & 0 & 48 & 17.49 & 13.934 \\
\hline & $\begin{array}{l}\text { Number Of Other College Courses } \\
\text { In the same Subject Area taken }\end{array}$ & 38 & 0 & 3 & .58 & .826 \\
\hline & Overall Credits This Semester & 45 & 3 & 19 & 14.09 & 3.281 \\
\hline & $\begin{array}{l}\text { Number Of Classes Taken This } \\
\text { Term }\end{array}$ & 39 & 3 & 6 & 4.92 & .774 \\
\hline & Hours Study per week & 36 & 0 & 12 & 3.19 & 2.376 \\
\hline & Hours Working For Pay Week & 45 & 0 & 50 & 15.76 & 13.432 \\
\hline & $\begin{array}{l}\text { Hours Working for pay X Credits } \\
\text { this semester }\end{array}$ & 45 & 0 & 760 & 226.02 & 198.768 \\
\hline
\end{tabular}

\section{DATA}

Data was collected during the Spring 2009 semester from a set of sections of the same hybrid course taught by the same instructor (the corresponding author). This study addresses 8 of those sections - Introduction to Computers in Business course - for a 216 students. Data utilized includes the grades from that semester, data from the vendor providing online videos to students (e.g., time spent with videos), and an end of course evaluation survey. The end of course survey included a question asking students for permission to use that survey for the purposes of research on the part of the course instructor and co-authors of this paper. Of the 216 students in these sections, 139 completed the course evaluation survey, and 31 did not consent to have their survey information used for research, resulting in an 108 cases used. No significant difference in means regarding variables used in this study was found between those who did and did not provide permission. Some students did not respond to the survey. An independent samples T-Test of difference in means between those who did respond and those who did not respond showed no statistically significant difference for outcome or control variables. 
Table 4

Descriptive statistics

\begin{tabular}{|c|c|c|c|}
\hline \\
\hline Variable & Treatment & Control & Totals \\
\hline \multicolumn{4}{|l|}{ Gender - } \\
\hline Male & 21 & 22 & 43 \\
\hline Female & 15 & 17 & 32 \\
\hline Missing & 36 & 39 & 75 \\
\hline \multicolumn{4}{|l|}{ Level } \\
\hline Freshman & 10 & 9 & 19 \\
\hline Sophmore & 9 & 11 & 20 \\
\hline Junior & 5 & 2 & 7 \\
\hline Senior & 11 & 16 & 27 \\
\hline Missing & 27 & 8 & 35 \\
\hline \multicolumn{4}{|l|}{ Ethnic background } \\
\hline Afro-American or Black & 4 & 5 & 9 \\
\hline Asian-American & 7 & 5 & 12 \\
\hline Caucasian & 18 & 15 & 33 \\
\hline Hispanic or Spanish speaking & 7 & 7 & 14 \\
\hline Missing & 26 & 8 & 34 \\
\hline
\end{tabular}

An independent samples t-test of difference in means between the treatment and control sections was carried out to test all hypotheses and to evaluate control variables (evaluate alternative explanations to hypotheses). A two-tailed statistical significance level of $\mathrm{p}<=.05$ was used as a rule of thumb for determining whether to reject the null hypothesis of no difference in means (Garson, 2009).

The instructor and two graduate students graded all assignments except for the exams which were automatically graded by a service provider. Analyzing the previous semester's data, no difference in means between graders (the same people) was found for most assignments, with the exception of the first homework, which is part of the Word/Powerpoint module. This problem persisted for Module 1 in the semester in question for the Word/Powerpoint module (homework, and project/case study assignments). Work was done on the rubrics for grading and additional communication between graders for the following modules, and no difference in means for outcomes were found by grader for the following two modules in the course - the Excel and Access modules. Therefore, only those case studies and homework grades will be used as outcome variables in this study. No significant difference in grades in terms of grader was found for the Excel and Access case studies. In general, exam grades were not used in this study as outcome variables because of a difference in how they were carried out between control and treatment groups - outside of vs. in-class (Tuesday was not proctored, Thursday was).

\section{RESULTS}

Hypotheses are stated and results reported in terms of positive outcomes of the treatment - i.e., fewer missed assignments, higher grades. Differences between treatment and control groups were assessed via independent samples T-Tests, using two tailed criterion for statistical significance, and using a p level of $=<.05$. Given that, the null hypothesis for all hypotheses could not be rejected. Indeed, where difference in means was statistically significant, a negative outcome of treatment was found, i.e., the treatment group had more missed assignments, completed fewer tutorials and missed more assignments. The treatment (Tuesday) group in relation to the control (Thursday) group (see Table 5 below - note Mean Differences is treatment mean minus control mean. For the items measuring missed assignments, a positive figure means the treatment missed more than the control; for the other items, a negative figure means the treatment group did less well (e.g., grades):

- $\quad$ missed more assignments overall (1.37) (of 20)

- $\quad$ missed more homework assignments (.44) (of 7)

- $\quad$ missed completing more tutorials (.67) (of 7)

- $\quad$ put in less training time for 2 out of 7 sets of tutorials

- lower evaluation of class resources

○ in particular, a lower assessment of homework (discussed below) 
Only one statistically significant difference in means was found for grades regarding assignments that were comparable, i.e., where both treatment and control groups carried out work in the same way (both were not proctored). This includes case study grades, and homework assignments that met this criterion.

Table 5

Independent samples T-Test difference in means - statistically significant Outcome items* Mean

Difference

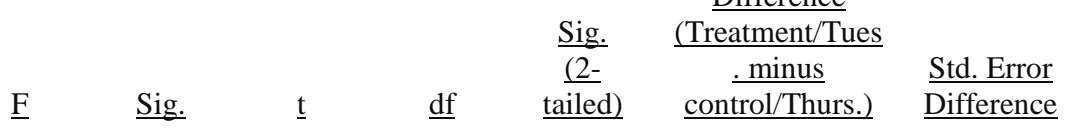

Buy-in: Complete assignments

Missed after two face to face meetings doing homework (after homework 3) (sum)

9.321

.003

2.350

85

.021

.90

.384

Missed Overall (sum)

$2.387 \quad 73.870$

.020

.90

.378

Missed HW (sum)
Missed Tutorials (sum)
Buy-in: Study Effort
Excel Training time (1 of 2 sets of
videos)

15.476

.000

3.215

$106 \quad .002$

1.37

.425

3.489

98.001

1.37

.392

$24.731 \quad .000$

3.120

106

.001

.143

3.390

97.538

.002

.45

.131

$21.479 \quad .000$

2.901

106

.005

.45

.232

3.148

98.145

.002

.67

.214

17.602

.000

$-1.922 \quad 106 \quad .057$

$-13$

6.68

Access Training time (1 of a set of 2 videos)

$\begin{array}{ll}39.630 & .000 \\ 24.818 & .000\end{array}$

$-2.051$

103.401

.043

$-13$

6.26

$-2.760 \quad 106 \quad .007$

$-18$

6.57

$-2.217$

106

.029

$-12$

5.57

$-2.465$

86.320

.016

$-12$

5.01

Grades

Access homework

14.742

.000

$\begin{array}{ccccc}-3.159 & 102 & .002 & -10 & 3.16 \\ -3.451 & 86.056 & .001 & -10 & 2.89 \\ -3.021 & 94.268 & .003 & -18 & 6.00\end{array}$

\section{Assessment of resources}

Mean of Professor knowledge, tutorials useful, homework helpful, Professor accessible, GA's accessible.

$\begin{array}{lllllll}1.093 & .298 & -2.133 & 105 & .036 & -.23 & .11\end{array}$

Homework assignments were appropriate for learning

.038

$-2.087 \quad 86.972 \quad .04$

Homework assignments were useful for reinforcing learning.

\begin{tabular}{|c|c|c|c|c|c|c|}
\hline \multirow[t]{2}{*}{ 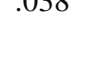 } & & 0.525 & & .022 & & \\
\hline & & -2.475 & 104.018 & .015 & -.33 & .135 \\
\hline \multirow[t]{3}{*}{6.814} & .010 & -2.280 & 106 & .025 & -.25 & .111 \\
\hline & & -2.223 & 87.103 & .029 & -.25 & .114 \\
\hline & & 2.061 & 93.684 & .042 & .85 & .413 \\
\hline
\end{tabular}

.413

\footnotetext{
* criterion: 2-way, $*_{-}=<.05, *_{-}=<, 01$; figures for each item include two lines of figures - assuming the same variance (first line) and not - second line)
} 


\section{POST HOC ANALYSIS}

At the very least, differences in structures did not have a clear positive impact. A systematically negative (and opposite of hypothesized) difference in means between the control and treatment groups on the other hand, was not expected and needs to be explained. There are two explanations - a here-to-for unidentified confounding variable(s) or that the change in course structure itself had a systematically negative rather than positive impact. Evidence against the first suggestion is provided by a previous study of the same course, and same sections found no difference in means in terms of GPA (Hollister and Berenson, 2009). On the other hand, GPA data was available for students in the semester in question. That data would have helped to more definitively rule out a change in the particular semester under study of the quality of students attending sections on Tuesdays vs. Thursdays.

There are several speculations that can be offered to explain results, some which can be assessed through futher post hoc analysis of data and others which cannot be. It is possible that a) students in the treatment group perceived interaction with instructors and peers in a negative light, so that more interaction meant perceptions of lower quality of course resources, and perhaps in turn lower performance; b) students may have been disappointed by the failure of the course to live up to expectations the course as a hybrid course, i.e., being asked to come to class frequently in the beginning of the course. Students may have felt that doing work in class was more of a burden rather than as an opportunity.

The former speculation was assessed by looking at student perceptions of the instructor, and graduate assistants. No statistically significant difference in means was found in analyzing the end of course evaluation survey questions concerning: a) knowledge of the instructor, b) accessibility of the instructor, c) accessibility of the graduate assistants.

Students may have resented or disliked the face to face requirements given the promise of convenience of a hybrid course. This speculation is supported by looking at the difference in means regarding the assignments where students were required to attend face-to-face sessions in the treatment group. The treatment group had a statistically significant lower mean score in their evaluation of homework - whether it was appropriate for learning (.33 lower mean on scale of 7), and helpful in reinforcing skills (.25 lower mean on a scale of 1 to 7) (See table 5 above). Interestingly, there was no significant difference in means in responses to course evaluation survey items regarding whether students would take another hybrid course or whether a hybrid course was appropriate for learning.

\section{CONCLUSION}

Studies cited in this paper look at hybrid course structure and garner feedback from teachers and students about hybrid classes in graduate courses. This paper looks at an undergraduate course, and specifically one at the second year level. It may be that results would be different for graduate students, or might vary by type of course (this course involved instruction on computer business applications). It is theoretically postulated by some studies cited in this paper that increased quantity and quality of contact in the beginning of a hybrid course leads to increased social and cognitive identification with the course - instructor and peers - and that this in turn would impact motivation and information transfer. Clearly, the data gathered for this study suggest that this assumption should be questioned, at least in terms of the level of students and perhaps the subject matter of the course.

In addition, this study inspires further theoretical speculation on the precise process by which face to face interaction leads to social identification on the part of the student with the course (instructor, peers, or a cognitive image of the course). How much interaction is needed, over what length of time? What sorts of interaction are necessary? What student factors and instructor factors are important in this process? In this case, 'quality' was operationalized as greater freedom of students to interact with the instructor, graduate assistants, and peers. Perhaps simply greater freedom for students as individuals to interact with instructors and peers does not lead to the quality of interaction necessary. This one-to-many structure might enable some especially outgoing and sociable students, but would not provide sufficient conditions for organic social development to occur. Future studies might look at face to face meetings that are structured differently to enhance their quality, such as forming small groups that might meet repeatedly. Or perhaps face to face meetings might be more fruitful in terms of fostering social identification with the course if sessions were systematically orchestrated by instructors rather than allowing students as 
individuals to interact at will might lead to different outcomes. In any case, use of a specific theory of social interaction and social identification in courses is called for - how to conceptualize, assess and related outcomes.

One possible reason for the outcomes might be that treatment students had a practical disadvantage in being required to work face to face in class. Students are more constrained in terms of time and place to work on and submit their assignment. Overall student schedule flexibility is reduced. Students in the control group simply accessed the web based courseware and submitted completed assignments before the deadline (midnight of the same day). Thus, those who did not have to come to class might have had an advantage in that they could have had greater control over how and when to carry out their work. On the other hand, students who might not ordinarily come into lab/office hours to interact with instructors or peers might have done do given the requirement to do the assignment in class.

Future studies should assess motivations for students in taking the hybrid course - it could be that convenience of working outside of class meetings is a primary benefit seen by students. Therefore, a proper role for mandatory face to face meetings might be theorized or whether those meetings provided added value at all (i.e., why not just have an entirely on-line course?). Obviously, greater controls should be utilized if possible, especially GPA, and perhaps a survey of student study orientations, such as the Motivated Strategies for Learning Questionnaire (Pintrich, 2003).

\section{BIBLIOGRAPHY}

1. Chaney, B. History, Theory, and Quality: Indicators of Distance Education: A Literature Review, Beth H. Chaney, Ph.D., CHES, Office of Health Informatics, Teas A\&M University

2. D. Randy Garrison, \& Vaughan, N. D. (2008). Blended Learning in Higher Education: Framework, Principles, and Guidelines. Jossey-Bass.

3. Dziuban, C., Hartman, J., Juge, F., Moskal, P., \& Sorg, S. (2006). Blended learning enters the mainstream. The handbook of blended learning: Global perspectives, local designs, 195-206.

4. Dziuban, C., Hartman, J., Moskal, P., Sorg, S., \& Truman, B. (2004). Three ALN modalities: An institutional perspective. Elements of quality online education: Into the mainstream, 127-148.

5. Dziuban, C., Moskal, P., \& Hartman, J. (2005). Higher education, blended learning and the generations: Knowledge is power-no more. Elements of quality online education: Engaging communities. Needham, MA: Sloan Center for Online Education.

6. Dziuban, C., Moskal, P., Brophy, J., \& Shea, P. (2007). Student Satisfaction with Asynchronous Learning. Journal of Asynchronous Learning Networks, 11(1), 87-95.

7. Garson, G. David (2009). "Title of Topic", from Statnotes: Topics in Multivariate Analysis. Retrieved 05/08/09 from http://faculty.chass.ncsu.edu/garson/pa765/statnote.htm.

8. Graham, C. R. \& Dziuban, C. (2007). "Blended Learning Environments" in Handbook of research on educational communications and technology, pgs. 269-76. $3^{\text {rd }}$ edition. Edited by j. Michael spector, $\mathrm{m}$. david merrrill, jeroen van merrienboer, marcy p. driscoll. Lawrence Erlbaum associates: new York.

9. Hollister, K. K., \& M. L. Berenson. (2009). Proctored Versus Unproctored Online Exams: Studying the Impact of Exam Environment on Student Performance. Decision Sciences Journal of Innovative Education, Volume 7, No. 1.

10. Huang, H. M. (2002). Student perceptions in an online mediated environment. International Journal of Instructional Media, 29(4), 405-422.

11. Kumrow, D. E. (2007). Evidence-Based Strategies of Graduate Students to Achieve Success in a Hybrid Web-Based Course. Journal of Nursing Education, 46(3), 140-145

12. Menchaca, M. P., \& Bekele, T. A. (2008). Learner and instructor identified success factors in distance education. Distance Education, 29(3), 231-252

13. Perna, Laura W. \& Scott L. Thomas (2008). Theoretical Perspectives on Student Success: Understanding the Contributions of the Disciplines. Wiley/Jossey-Bass.

14. Pintrich, P. R. (2003). A Motivational Science Perspective on the Role of Student Motivation in Learning and Teaching Contexts. Journal of Educational Psychology, 95(4), 667-86.

15. Senn, G. J. (2008). Comparison of Face-To-Face and Hybrid Delivery of a Course that Requires Technology Skills Development. Journal of Information Technology Education, 7, 267-283. doi: Article. 